\title{
PERBANDINGAN IBU HAMIL YANG MELAKUKAN EXERCISE GYM $B A L L$ DAN IBU HAMIL YANG MELAKUKAN SENAM HAMIL TERHADAP PENURUNAN NYERI PUNGGUNG BAWAH
}

\author{
Comparison of pregnant mother which gymnastic ball and pregnant exercise \\ Against decrease lawer back pain \\ Irfana Tri Wijayanti ${ }^{1}$ \\ STIKes Bakti Utama Pati \\ (irfana_tri@yahoo.co.id)
}

\begin{abstract}
ABSTRAK
Latar Belakang : Sekitar 50-70\% dari wanita hamil dapat merasakan nyeri punggung bawah. Nyeri punggung bawah dirasakan saat kehamilan trimester II dan III dan dapat menggangu aktifitas fisik sehari-hari seperti naik tangga, berjalan, bekerja berat, berpartisipasi dalam latihan, terganggu kualitas tidur.

Tujuan : Penelitian ini bertujuan untuk mengetahui perbandingan ibu hamil yang melakukan exercise gym ball dan ibu hamil yang melakukan senam hamil terhadap penurunan nyeri punggung bawah.

Metode : Penelitian ini merupakan penelitian quasi eksperimen dengan pre test dan post test. Populasi penelitian ini adalah ibu hamil trimester III primigravida. Subyek berjumlah 28 orang. Pada penelitian ini menggunakan alat pengumpul data berupa kuesioner tertutup dengan numeric rating scale boubonis. penelitian ini di klinik lydia syfra dan klinik budi luhur. Analisa data menggunakan wilcoxon sedangkan uji perbandingan menggunakan mann whitney.

Hasil : Prevalensi umur ibu hamil mayoritas 24-29 tahun sebanyak 9 (64,3\%). pendidikan mayoritas tamat perguruan tinggi sebanyak $11(78,6 \%)$, pekerjaan swasta sebanyak $7(50 \%)$. Sifat nyeri mayoritas tertusuk sebanyak $8(57,2 \%)$. Untuk mengatasi nyeri mayoritas membiarkan dan melakukan olahraga sebanyak 7 (42,9\%), sedangkan pada kelompok senam hamil mayoritas berobat ke tenaga kesehatan sebanyak $5(35,7 \%)$. Nilai $p$ value $=0,000<0,05$ yang artinya ada perbedaan penurunan nyeri punggung pada ibu hamil trimester III sebelum dan sesudah pada kelompok exercise gym ball sebesar 3.01 sedangkan kelompok senam hamil rata-rata penurunan tingkat nyeri punggung sebesar 1,33. Hal ini membuktikan bahwa exercise gym ball lebih berpengaruh terhadap penurunan nyeri dibandingkan dengan yang senam hamil
\end{abstract}

Simpulan: Exercise gym ball lebih berpengaruh terhadap penurunan nyeri dibandingkan dengan yang senam hamil.

Kata kunci: Exercise gym ball, senam hamil, nyeri punggung bawah, ibu hamil TM III 


\begin{abstract}
Background:, About 50-70\% of pregnant women can feel low back pain. Lower back pain is felt during the second and third trimester of pregnancy and can interfere with daily physical activities such as climbing stairs, walking, working hard, participating in exercise, disturbed sleep quality.

The Aim: This study aims to determine the comparison of pregnant women who do gym ball exercises and pregnant women who do pregnancy exercises to reduce lower back pain.

Method: This research is a quasi-experimental study with pre-test and post-test. The population of this research is primigravida third trimester pregnant women. Subjects numbered 28 people. In this study using a data collection tool in the form of a closed questionnaire with numerical rating scale boubonis. this research in lydia syfra clinic and benevolent clinic. Data analysis uses Wilcoxon while the comparative test uses Mann Whitney.

Results: The prevalence of the majority of pregnant women aged 24-29 years was $9(64.3 \%)$. majority education graduated from tertiary institutions by 11 (78.6\%), private employment by 7 (50\%). The majority of the nature of pain punctured by 8 (57.2\%). To overcome the pain the majority let and do sports as much as 7 $(42.9 \%)$, while in the group of pregnancy exercise the majority went to health workers as much as $5(35.7 \%)$. The value of $p$ value $=0,000<0.05$, which means there is a difference in the decrease in back pain in third trimester pregnant women before and after the gym ball group of 3.01 while the group of pregnant gymnastics decreased the average level of back pain by 1.33. This proves that gym ball exercises have more effect on pain reduction compared to pregnant gymnastics
\end{abstract}

Conclusion: Exercise gym ball is more influential on decreasing pain compared to pregnant gymnastics.

Keywords: Exercise gym ball, pregnancy exercise, low back pain, TM III pregnant women

\title{
PENDAHULUAN
}

Pada awal kehamilan biasanya ibu hamil mengalami mual, muntah, merinag dan lemas. Pada trimester kedua dan trimester ketiga mengalami pembesaran perut, perubahan anatomis dan perubahan hormonal akan menyebabkan munculnya keluhan-keluhan tersebut diantaranya adalah nyeri punggung, sesak nafas, varises, hemorrhoid, konstipasi, gangguan tidur dan lain-lain (Indriyani, 2011). Penyebab nyeri punggung pada ibu hamil sebagai konsekuensi perubahan tubuh dan perkembangan janin beserta perangkatnya seperti plasenta, air ketuban dan Rahim, peningkatan hormone-hormon, perubahan dalam mobilitas sendisendi serta melenturkan ligament-ligamen dan meregangnya otot-otot abdomen, postur atau posisi yang tidak baik seperti membungkuk dan stress akibat perubahan fisik. Hal ini menyebabkan ketidaknyamanan dalam melakukan aktivitas (Bisma Bratayatnya, 2008)

Perbandingan Ibu Hamil Yang Melakukan Exercise Gym Ball Dan Ibu Hamil Yang Melakukan Senam Hamil Terhadap Penurunan Nyeri Punggung Bawah (Irfana Tri Wijayanti) 
Lebih dari dua pertiga ibu hamil mengalami sakit punggung dan hamper satu perlima mengalami nyeri punggung bawah yang dialami akan memicu terjadinya stress dan perubahan mood pada ibu hamil yang berujung terhadap semakin memburuknya nyeri punggung bawah (Association Chartred Physiotherapis For Woman Health, 2011). Nyeri punggung bawah sering di perparah dengan terjadinya backache (nyeri punggung yang lama) ditemukan pada $45 \%$ wanita saat dicatat kehamilannya, meningkat $69 \%$ pada minggu ke 28 dan hamper bertahan pada tingkat tersebut (Mander, 2004). Prevalensi terjadinya nyeri punggung bawah pada ibu hamil terjadi lebih dari 50\% di Amerika serikat, Kanada, Iceland, Korea, Turki. Sementara yang terjadi di Negara Non Skandivia seperti Amaerika Utara, Afrika lebih tinggi prevalensinya yang berkisar antara 21\% hingga 89,9\% (Anshari, 2009).

Hasil SDKI 2012 menunjukan ada persoalan dalam pencapaian target penurunan AKI, AKB, dan AKABA. Indikator AKB turun sedikit dari pencapaian tahun 2007, yaitu dari 34/1.000 kelahiran hidup menjadi 32/1.000 kelahiran hidup. Indikator AKABA dalam SDKI 2012 yaitu 43/ 1.000 kelahiran hidup turun menjadi 40/1.000 kelahiran hidup. Sedangkan terjadi peningkatan pada AKI, yaitu 359/100.000 kelahiran hidup. Angka ini lebih besar dibandingkan pencapaian tahun 2007, yaitu 228/100.000 kelahiran hidup. (BKKBN, 2013) Padahal, bila dibandingkan dengan target pencapain MDG's untuk Indonesia tahun 2015, diharapkan AKI turun menjadi 102/100.000 kelahiran hidup, AKB 23/1.000 kelahiran hidup, dan AKABA 32/1.000 kelahiran hidup (Bappenas, 2012). Sedangkan data Kementerian Kesehatan tahun 2015 AKI di Indonesia mencapai 305 per 100.000 kelahiran hidup. Sedangkan AKB mencapai 32 per 1000 kelahiran hidup.

Upaya yang dapat dilakukan untuk mengurangi dan mencegah nyeri punggung perlu diberikan latihan-latihan dan olahraga seperti gym ball, senam hamil atau latihan fisik lainnya. Gym ball, senam hamil merupakan salah satu pengobatan komplementer. Penyelenggaraan pengobatan komplementer alternatif di fasilitas pelayanan di Indonesia telah diatur pada peraturan menteri kesehatan Republik Indonesia Nomor 1109/Menkes/Per/IX/2007 pasal 3 yang berbunyi "pengobatan komplementer alternatif dilakukan sebagai upaya pelayanan yang berkesinambungan mulai dari peningkatan kesehatan (Promotif), pencegahan penyakit (preventif), penyembuhan penyakit (kuratif) dan atau pemulihan kesehatan (rehabilitatif).

Penelitian tentang birth ball yang dilakukan oleh Kwan et al (2011) yaitu evaluasi penggunaan birth ball pada intrapartum. Sebanyak 66\% melaporkan penurunan tingkat nyeri setelah menggunakan birth ball, 8\% melaporkan nyeri yang lebih dari sebelumnya, $26 \%$ melaporkan tidak ada perubahan dalam tingkat nyerinya. Pada kepuasan pemakaian, $84 \%$ menyatakan birth ball dapat meredakan nyeri kontraksi, 79\% dapat meredakan nyeri punggung dan 95\% menyatakan nyaman ketika menggunakan birth ball. Sedangkan menurut Yu (2010) salah satu cara untuk meningkatkan kesehatan selama kehamilan adalah dengan melakukan olah raga ringan seperti senam hamil. Senam hamil adalah suatu bentuk latihan guna memperkuat dan mempertahankan elastisitas otot-otot dinding perut, ligamenligamen, serta otot dasar panggul yang berhubungan dengan proses 
persalinan. Latihan ini berfungsi untuk memperkuat stabilitas inti tubuh yang akan membantu memelihara kesehatan tulang belakang. Mempunyai kekuatan tubuh yang baik dapat meningkatkan keseimbangan dan kestabilan individu serta meminimalkan risiko trauma tulang belakang ataupun jatuh pada saat hamil.

Hasil wawancara pada 5 ibu hamil TM III, 3 ibu hamil mengalami nyeri punggung bawah yang mengganggu aktivitasnya. Sedangkan 2 ibu hamil mengalami mengeluh nyeri punggung bawah tapi tidak mengganggu aktivitasnya. Berdasarkan latar belakang di atas, penulis tertarik untuk melakukan penelitian tentang "Perbandingan Ibu Hamil Yang Melakukan Exercise Gym Ball dan Ibu Hamil Yang Melakukan Senam Hamil Terhadap Penurunan Nyeri Punggung Bawah".

\section{METODE PENELITIAN}

Penelitian ini merupakan penelitian quasi eksperimen dengan pre test dan post test. Populasi penelitian ini adalah ibu hamil trimester III primigravida di Klinik Lydia Syfra. Subyek berjumlah 28 orang. Pada penelitian ini menggunakan alat pengumpul data berupa kuesioner, jenis kuesioner dalam penelitian ini adalah kuesioner tertutup dengan numeric rating scale boubonis. Metode pengumpulan data yang digunakan adalah pengumpulan data primer dan data sekunder. Analisa data dalam penelitian ini menggunakan paired $t$ test.

\section{HASIL DAN PEMBAHASAN}

\section{Hasil}

Tabel 1 Distribusi Frekwensi Karakteristik Subyek Penelitian

\begin{tabular}{lcccc}
\hline \multicolumn{1}{c}{ Karakteristik } & \multicolumn{2}{c}{ Kelompok Gym Ball } & \multicolumn{2}{c}{ Kelompok Senam Hamil } \\
\cline { 2 - 5 } Umur Penelitian & $\mathrm{N}$ & $\%$ & $\mathrm{n}$ & $\%$ \\
\hline 24-29 Tahun & 9 & $64,3 \%$ & 10 & $71,4 \%$ \\
30-36 Tahun & 5 & $35,7 \%$ & 4 & $28,6 \%$ \\
Pendidikan & & & & \\
SLTP & 0 & $0 \%$ & 1 & $7,1 \%$ \\
SLTA & 3 & $21,4 \%$ & 6 & $42,9 \%$ \\
PT & 11 & $78,6 \%$ & 7 & $50 \%$ \\
Pekerjaan & & & & \\
Swasta & 6 & $42,9 \%$ & 7 & $50 \%$ \\
Wiraswasta & 4 & $28,6 \%$ & 0 & $0 \%$ \\
Negeri & 1 & $7,1 \%$ & 1 & $7,1 \%$ \\
IRT & 3 & $21,4 \%$ & 6 & $42,9 \%$ \\
Sifat Nyeri & & & & \\
Tertusuk & 8 & $57,2 \%$ & 6 & $42,9 \%$ \\
Tajam & 3 & $21,4 \%$ & 7 & $50 \%$ \\
Biasa & 3 & $21,4 \%$ & 1 & $7,1 \%$ \\
Mengatasi Nyeri & & & & \\
Membiarkan & 7 & $50 \%$ & 4 & $28,6 \%$ \\
Berobat & & & 5 & $35,7 \%$ \\
Olahraga & 6 & $42,9 \%$ & 1 & $7,1 \%$ \\
Minum Susu Hamil & & $7,1 \%$ & 1 & $7,1 \%$ \\
Gosok minyak kayu putih & 1 & & \\
\hline
\end{tabular}




\begin{tabular}{lcccc}
\hline Karakteristik & \multicolumn{2}{c}{ Kelompok Gym Ball } & \multicolumn{2}{c}{ Kelompok Senam Hamil } \\
\cline { 2 - 5 } Subyek Penelitian & $\mathrm{N}$ & $\%$ & $\mathrm{n}$ & $\%$ \\
\hline Berbaring & & & 3 & $21,5 \%$ \\
\hline
\end{tabular}

Berdasarkan Tabel 1. menunjukkan bahwa prevalensi umur ibu hamil mayoritas berumur 24-29 tahun pada kelompok gym ball sebanyak $9(64,3 \%)$ dan kelompok senam hamil sebanyak $10(71,4 \%)$. Untuk pendidikan mayoritas tamat perguruan tinggi pada kelompok gym ball sebanyak $11(78,6 \%)$, kelompok senam hamil 7 (50\%). Untuk pekerjaan sebagian besar bekerja swasta pada kelompok gym ball sebanyak $6(42,9 \%)$ sedangkan pada kelompok senam hamil sebanyak 7 $(50 \%)$. Sifat nyeri mayoritas bersifat tertusuk pada kelompok gym ball sebanyak 8 $(57,2 \%)$, sedangkan pada kelompok senam hamil mayoritas bersifat tajam sebanyak 7 (50\%). Untuk mengatasi nyeri pada kelompok gym ball mayoritas membiarkan dan melakukan olahraga sebanyak 7 (42,9\%), sedangkan pada kelompok senam hamil mayoritas berobat ke tenaga kesehatan sebanyak 5 $(35,7 \%)$.

Tabel 2 Gambaran Tingkat Nyeri Punggung Sebelum dan Sesudah Exercise Gym Ball

\begin{tabular}{llcccc}
\hline \multirow{2}{*}{ Tingkat Nyeri } & \multicolumn{2}{c}{ Sebelum } & \multicolumn{2}{c}{ Sesudah } \\
& $\mathrm{n}$ & - & - & 1 & $7,1 \%$ \\
\hline 0 & : Tidak Nyeri & 2 & $14,3 \%$ & 12 & $85,8 \%$ \\
$1-3$ & : Nyeri Ringan & 11 & $78,6 \%$ & 1 & $7,1 \%$ \\
$4-6$ & : Nyeri Sedang & 1 & $7,1 \%$ & & \\
$7-9$ : Nyeri Berat Terkontrol & - & - & & \\
$10:$ Berat Tidak Terkontrol & & &
\end{tabular}

Pada tabel 2 menunjukkan data sebelum exercise gym ball tingkat nyeri punggung pada ibu hamil trimester III sebanyak $11(78,6 \%)$ berada pada skala nyeri sedang. Namun setelah exercise gym ball tingkat nyeri punggung ibu hamil trimester III menunjukkan penurunan nyeri yaitu $12(85,8 \%)$ berada pada skala nyeri ringan.

Tabel 3 Gambaran Tingkat Nyeri Punggung Sebelum dan Sesudah Senam Hamil

\begin{tabular}{llcccc}
\hline \multirow{2}{*}{ Tingkat Nyeri } & \multicolumn{2}{c}{ Sebelum } & \multicolumn{2}{c}{ Sesudah } \\
& $\mathrm{N}$ & - & $\mathrm{N}$ & $\%$ \\
\hline 0 & : Tidak Nyeri & - & $57,1 \%$ & 10 & $21,4 \%$ \\
$1-3$ & : Nyeri Ringan & 4 & $28,6 \%$ & 1 & $7,5 \%$ \\
$4-6$ & : Nyeri Sedang & 2 & $14,37 \%$ & & \\
$7-9$ & : Nyeri Berat Terkontrol & - & - & \\
$10:$ Berat Tidak Terkontrol & - & &
\end{tabular}

Berdasarkan tabel 3 menunjukkan data sebelum,tingkat nyeri punggung pada ibu hamil trimester III sebanyak $8(57,1 \%)$ berada pada skala nyeri sedang. Namun sesudah, tingkat nyeri punggung ibu hamil trimester III sebanyak 10 $(71,5 \%)$ berada pada skala nyeri ringan.

Perbandingan Ibu Hamil Yang Melakukan Exercise Gym Ball Dan Ibu Hamil Yang Melakukan Senam Hamil Terhadap Penurunan Nyeri Punggung Bawah 
Tabel 4 Rata-Rata Intensitas Nyeri Pre dan Post Test Pada Kelompok Exercise Gym Ball

\begin{tabular}{llcc}
\hline \multicolumn{1}{c}{ Variabel } & $\mathrm{N}$ & Mean $\pm \mathrm{SD}$ & P value \\
\hline Sebelum & 14 & $4,73 \pm 1,22$ & 0,000 \\
Sesudah & 14 & $2,10 \pm 1,04$ & \\
\hline
\end{tabular}

Pada tabel 4 nyeri punggung bawah ibu hamil trimester III pada kelompok exercise gym ball menggunakan uji Wilcoxon. Berdasarkan uji tersebut, menunjukkan nilai $\mathrm{p}$ value $=0,000<0,05$ yang artinya ada perbedaan nyeri punggung pada ibu hamil trimester III sebelum dan sesudah pada kelompok intervensi. Nilai rata-rata sebelum exercise gym ball sebesar 4,73 $\pm 1,22$ dan sesudah exercise gym ball rata-rata nyeri turun menjadi $2,10 \pm 1,04$.

Tabel 5 Rata-Rata Intensitas Nyeri Pre dan Post Test Pada Kelompok Senam Hamil

\begin{tabular}{llcc}
\hline \multicolumn{1}{c}{ Variabel } & $\mathrm{N}$ & Mean $\pm \mathrm{SD}$ & P value \\
\hline Sebelum & 14 & $3,62 \pm 1,75$ & 0,01 \\
Sesudah & 14 & $2,10 \pm 1,31$ & \\
\hline
\end{tabular}

Pada tabel 5 nyeri punggung bawah ibu hamil trimester III pada kelompok tidak exercise gym ball menggunakan uji Wilcoxon. Berdasarkan uji tersebut, menunjukkan nilai $\mathrm{p}$ value $=0,01<0,05$ yang artinya ada perbedaan nyeri punggung pada ibu hamil trimester III sebelum dan sesudah pada kelompok kontrol. Nilai rata-rata sebelum sebesar 3,62 $\pm 1,75$ dan sesudah rata-rata nyeri turun menjadi $2,10 \pm 1,31$.

Tabel 6 Perbandingan Ibu Hamil Melakukan Exercise Gym Ball dan Ibu Hamil Melakukan Senam Hamil Terhadap Penurunan Nyeri Punggung Bawah

\begin{tabular}{lcccc}
\hline \multicolumn{1}{c}{ Kelompok } & Mean & SD & SD Mean & P Value \\
\hline Exercise Gym Ball & 3.01 & .55 & .16 & 0,000 \\
Senam Hamil & 1.33 & 1.63 & .43 & \\
\hline
\end{tabular}

Pada tabel 6 menunjukkan nilai $\mathrm{p}$ value $=0,000<0,05$ yang artinya ada perbedaan penurunan nyeri punggung pada ibu hamil trimester III sebelum dan sesudah pada kelompok exercise gym ball sebesar 3.01 sedangkan kelompok senam hamil rata-rata penurunan tingkat nyeri punggung sebesar 1,33. Hal ini membuktikan bahwa exercise gym ball lebih berpengaruh terhadap penurunan nyeri dibandingkan dengan yang senam hamil.

\section{Pembahasan}

Rata-rata Ibu hamil trimester III sering mengalami nyeri punggung bawah. Hal ini disebabkan pergeseran pusat grafitasi wanita, postur tubuhnya semakin lordosis, berat uterus yang semakin membesar, membungkuk berlebihan, berjalan tanpa istirahat dan angkat beban (Varney, 2006). Hasil penelitian 9 ibu hamil 
trimester III pada kelompok intervensi mengalami nyeri yang bersifat tertusuk. Hal ini dikarenakan nosireseptor kutaneous berasal dari kulit dan sub kutan. Nyeri yang berasal dari daerah ini biasanya mudah untuk dialokasikan dan didefinisikan. Reseptor A delta mempunyai karakteristik menghantarkan nyeri, termielinisasi, sensasi tertusuk sensasi jelas dan teralokasi, ambang batas nyeri relatif sama dengan semua orang (strong et al, 2002).

Hasil penelitian Balakrishnan (2016), gym bal/l swiss ball merupakan pilihan terapi konservatif dengan menggunakan bola dimana tubuh merespon secara otomatis terhadap ketidakstabilan. Seiring berjalannya waktu, otot punggung dan abdomen yang digunakan untuk menjaga keseimbangan pada swiss ball akan menjadi lebih kuat. Latihan core strengthening akan meningkatkan kekuatan otot-otot stabilisator trunkus seperti otot multifidus, erector spinae dan abdominal.

Metode lain untuk mengatasi nyeri punggung pada ibu hamil dapat dengan melakukan aktivitas dengan hati-hati dan benar agar tidak terjadi kesalahan postur tubuh selain itu nyeri punggung pada ibu hamil juga dapat di atasi dengan olahraga yang sesuai dengan kemampuan ibu hamil salah satunya dengan melakukan senam hamil. Senam hamil yang dilakukan secara teratur dapat mengurangi nyeri punggung karena gerakan yang terdapat didalam senam hamil mampu memperkuat otot abdomen sehingga mencegah tegangan yang berlebihan pada ligamen pelvis sehingga intensitas nyeri punngung menjadi berkurang. Selain itu melakukan senam hamil mampu mengeluarkan endorphin didalam tubuh, dimana fungsi endorphin yaitu sebagai penenenang dan mampu mengurangi nyeri punggung pada ibu hamil. Dengan demikian pada penelitian ini dapat disimpulkan bahwa pemberian senam hamil dapat menurunkan intensitas nyeri punggung pada ibu hamil.

Hal ini sesuai dengan penelitian yang dilakukan oleh Puspitasari (2013) tentang hubungan senam hamil dengan nyeri punggung pada ibu hamil di Rumah Sakit Kendangsari Surabaya dengan hasil $p$ value $=0,000$ yang artinya Ho ditolak artinya adanya hubungan yang bermakna antara ibu hamil yang melakukan senam hamil dengan nyeri punggung. Semakin teratur ibu hamil dalam mengikuti senam hamil maka hal ini dapat meminimalkan nyeri punggung yang dirasakan oleh ibu hamil.

Teori gate control yang dikemukakan oleh Melzack dan Wall (1965) menjelaskan bahwa substansi gelatinosa (SG) yang berada pada bagian spinal cord mempunyai peranan sebagai pintu gerbang (gatting mechanism), mekanisme gate kontrol ini dapat memodifikasi dalam merubah sensasi nyeri yang datang sebelum mencapai korteks serebri dan menimbulkan rasa nyeri. Perubahan dalam waktu aktivasi otot abdominal ini mengarahkan kita kepada penggunaan latihan core strengthening. Latihan core strengthening dapat menggunakan gym ball untuk merubah sensasi dan mengobati nyeri punggung bawah. Selain itu juga kelemahan pada komplesitas panggul dan lumbo pelvis berkaitan kronik instabilitas.

Latihan core strengthening akan meningkatkan kekuatan otot-otot stabilisator trunkus seperti otot multifidus, erector spinae dan abdominal (transversus, rektus, dan oblikus). Penelitian oleh Yu, et al (2013) menunjukkan 
peningkatan amplitudo pada otot-otot erector spinae, multifidus, dan abdominal. Selanjutnya latihan ini juga dapat memberikan input pada sistem saraf pusat untuk meningkatkan aktivitas otot-otot trunkus tersebut. Efek positif lain dari latihan core strengthening adalah motor relearning yang akan mengurangi ketidakseimbangan kerja otot sehingga meningkatkan efisiensi gerak.

\section{SIMPULAN DAN SARAN}

\section{Simpulan}

Prevalensi umur ibu hamil mayoritas berumur 24-29 tahun sebanyak 9 $(64,3 \%)$. Untuk pendidikan mayoritas tamat perguruan tinggi sebanyak 11 $(78,6 \%)$. Untuk pekerjaan sebagian besar bekerja swasta sebanyak 7 (50\%). Sifat nyeri mayoritas bersifat tertusuk sebanyak $8(57,2 \%)$. Untuk mengatasi nyeri pada mayoritas membiarkan dan melakukan olahraga sebanyak 7 (42,9\%), sedangkan pada kelompok senam hamil mayoritas berobat ke tenaga kesehatan sebanyak 5 $(35,7 \%)$.

Hasil perbandingan menunjukkan nilai $p$ value $=0,000<0,05$ yang artinya ada perbedaan penurunan nyeri punggung pada ibu hamil trimester III sebelum dan sesudah pada kelompok exercise gym ball sebesar 3.01 sedangkan kelompok senam hamil rata-rata penurunan tingkat nyeri punggung sebesar 1,33. Hal ini membuktikan bahwa exercise gym ball lebih berpengaruh terhadap penurunan nyeri dibandingkan dengan yang senam hamil

\section{Saran}

Bagi tenaga kesehatan perlu dilakukan promosi tentang exercise gym ball berupa penyuluhan maupun poster bergambar pada ibu hamil untuk mengurangi keluhan nyeri punggung bawah. Bagi peneliti selanjutnya melakukan penelitian lanjutan dengan jumlah subyek penelitian lebih dari 15 subyek penelitian dengan menggunakan eksperimen murni dan untuk menghindari faktor subyektifitas maka pengukuran skala nyeri menggunakan EKG.

\section{DAFTAR PUSTAKA}

American Pregnancy Organisation. (2014). Back Pain During Pregnancy. (Http://Americanpregnancy.Org/Pregnancy-Health/Back -Pain- DuringPregnancy/). American Pregnancy Association.

Balakrishman R., Yazid E., Mahat M.F. (2016). Effectiveness Of The Core Stabilization Exercise On Floor and Swiss Ball On Individual With Non Spesific Low Back Pain. Int J Phys Educ Sport Health. 2016;3;347-56.

Chung SH, Lee J. S., Yoon J. S. (2013). Effects Of Stabilization Exercise Using a Ball On Multifidus Cross Sectional Area in Patients With Chronic Low Back Pain. Korea Selatan. JSSM. 2013;12;533-41.

Gau M.L., Chang C.Y., Tian S.H., Lin K.C. (2011). Effects Of Birth Ball Exercise On Pain and Self Efficacy During Childbirth: a Randomised Controlled Trial In Taiwan. www.elsevier.com/midw 
Hurlocker, T.T. (2010). Pain Manajement in Total Joint Arthroplasty: A Historical Review. Journal Of The American Academic Of Orthoppaedic Surgeon. Volume 33. Issue 9: 14-19 doi: 10.3928/014774477-20100722-65

Kisner, C and Colby, LA. (2006). Therapeutic Exercise Foundation and Tehniques. F. Adavis Company. Philadelphia

Leifer. (2008). Maternity Nursing An Introductory. Missouri: Elsevier Sunder.

Maryani, T., Estiwidani, Dwiana. (2014). Terapi Birth ball berpengaruh terhadap lama kala II dan intensitas nyeri persalinan pada ibu bersalin primigravida di RB Kasih Ibu Yogyakarta. Jurnal Kesehatan Ibu dan Anak (S.I.), v.10, n. 2, p.22-27, apr.2017. ISSN 2599-3224. http://ejournal.poltekkesjogja.ac.id/index.php/JKIA/article/view/164

Peraturan Menteri Kesehatan Republik Indonesia Nomor: 1109/MENKES/PER/IX/2007 tentang Penyelenggaraan Pengobatan Komplementer Alternatif Di Fasilitias Pelayanan Kesehatan. Jakarta: PerMenKes

Srienda D., Yulinda. (2016). Efektifitas Latihan Birth Ball Terhadap Efikasi Diri Primipara dengan Persalinan Normal. Jurnal Ners dan Kebidanan Indonesia ISSN 2354-7642. Tersedia di http://ejournal.almaata.ac.id/index.php/JNKI

Varney, Helen. (2006). Buku Ajar Asuhan Kebidanan Vol 1. Jakarta: EGC

Yu S.H., Doo T.S. (2013). The Effect Of Core Stability Strength Exercise On Muscle Activity and Trunk Impairment Scale In Stroke Patients, Journal Of Exercise Rehabilitation. 2013 ; 9 (3) :362-36. DOI: 10.12965/jer.130042. http://www.researchgate.net $>$ publication 